\title{
PERFIS SOCIAIS, PRODUÇÃO CULTURAL E ATUAÇÃO POLÍTICA DOS MEMBROS DO INSTITUTO HISTÓRICO E GEOGRÁFICO \\ DO MARANHÃO (IHGM) 12
}

\author{
Karolline Cristine Reis Garces ${ }^{3}$
}

\begin{abstract}
RESUMO
O presente trabalho desenvolveu-se no âmbito do Laboratório de Estudos sobre Elites Políticas e Culturais, sob a coordenação dos professores doutores Igor Gastal Grill e Eliana Tavares dos Reis. Nesta pesquisa, o foco se dirige à investigação das condições e dos condicionantes do exercício do trabalho político e intelectual de alguns intérpretes do Maranhão - que se caracterizam como um grupo de "elite" composto por historiadores, jornalistas, antropólogos, geógrafos, advogados, engenheiros entre outros, pertencentes ao Instituto Histórico e Geográfico do Maranhão (IHGM) - mediante o estudo dos seus perfis e de sua produção escrita (crônicas, contos, poesias, literatura em geral, biografias etc.). Para tanto, foram examinadas as biografias de sessenta e quatro membros efetivos do IHGM, através do material hagiográfico retirado da própria revista da instituição. A partir desse material foram perseguidos alguns objetivos, tais como: apreender as propriedades sociais dos agentes; identificar as formas de intervenção que privilegiam no âmbito da cultura e da política; e examinar os princípios de legitimação e aferição de excelência social ativados nas estratégias de valorização dos membros da instituição. A operacionalização do estudo foi desenvolvida por intermédio da construção e análise de um banco de dados que reúne informações sobre origem geográfica, profissão e escolarização dos ascendentes, trajeto escolar, carreiras profissionais, publicações, cargos administrativos (na universidade ou em burocracias de governos), cargos eletivos e engajamentos diversos (sindicais, religiosos, em movimentos sociais etc.) dos agentes.
\end{abstract}

Palavras-chave: Elites. Política. Cultura. IHGM. Trajetórias.

\begin{abstract}
The present work was developed in the scope of the Laboratory of Studies on Political and Cultural Elites, under the coordination of the professors Igor Gastal Grill and Eliana Tavares dos Reis. In this specific research, the focus is on the investigation of the conditions and constraints of the political and intellectual work of some interpreters of Maranhão, in which they are characterized as a group of "elite" composed of historians, journalists, anthropologists, geographers, lawyers, engineers among others, belonging to the Historical and Geographical Institute of Maranhão (IHGM), through the study of their profiles and written production (chronicles, short stories, poetry, literature in general, biographies, etc.). . In order to do so, the biographies of sixty-four effective members of the IHGM were examined through hagiographic material taken from the institution's own journal. From this material were pursued some objectives as: to apprehend the social properties of the agents; identify the forms of intervention that favor culture and politics; and to examine the principles of legitimation and measurement of social excellence activated in the strategies of valuation of the members of the institution. The operation of the study was developed through the construction and analysis of a database that gathers information about geographical origin, occupation and schooling of the ascendants, school path, professional careers, publications, positions (university or government bureaucracies), elective positions and diverse engagements (union, religious, social movements, etc.) of the agents.
\end{abstract}

Keywords: Elites. Policy. Culture. IHGM. Trajectories.

\section{RESUMEN}

El presente trabajo se desarrolló en el ámbito del Laboratorio de Estudios sobre Elites Políticas y Culturales, bajo la coordinación de los profesores doctores Igor Gastal Grill y Eliana Tavares dos Reis. En esta investigación específica, el foco se dirige a la investigación de las condiciones y de los condicionantes del ejercicio del trabajo político e intelectual de algunos intérpretes de Maranhão, en el que se caracterizan como un grupo de "elite"

\footnotetext{
${ }^{1}$ DOI: http://dx.doi.org/10.5380/recp.v8i2.56298

${ }^{2}$ Submetido em: 30 de setembro de 2017. Aprovado em: 28 de outubro de 2017.

${ }^{3}$ Aluna de graduação do curso de Ciências Sociais da Universidade Federal do Maranhão, bolsista de Iniciação Científica (PIBIC/CNPQ) e integrante do grupo de pesquisa intitulado "Laboratório de Estudos sobre Elites Políticas e Culturais" (LEEPOC), vinculado ao Programa de Pós-Graduação de Ciências Sociais da Universidade Federal do Maranhão. E-mail: karolline24@gmail.com.
} 
GARCES, K. C. R. Perfis sociais, produção cultural e atuação política dos membros do Instituto Histórico e Geográfico do Maranhão

compuesto por historiadores, periodistas, antropólogos, geógrafos, abogados, ingenieros entre otros, pertenecientes al Instituto Histórico y Geográfico de Maranhão (IHGM), mediante el estudio de sus perfiles y de la producción escrita (crónicas, cuentos, poesías, literatura en general, biografías, etc.). Para esto, se examinaron las biografías de sesenta y cuatro miembros efectivos del IHGM a través del material hagiográfico retirado de la propia revista de la institución. A partir de ese material fueron perseguidos algunos objetivos, como aprehender las propiedades sociales de los agentes; identificar las formas de intervención que privilegian en el ámbito de la cultura y de la política; y examinar los principios de legitimación y evaluación de excelencia social activados en las estrategias de valorización de los miembros de la institución. La operación del estudio fue desarrollada por medio de la construcción y análisis de un banco de datos que reúne informaciones sobre origen geográfico, profesión y escolarización de los ascendientes, trayectoria escolar, carreras profesionales, publicaciones, cargos (en la universidad o las burocracias de gobiernos), cargos electivos y compromisos diversos (sindicales, religiosos, en movimientos sociales etc.) de los agentes.

Palabras clave: Elites. Política. Cultura. IHGM. Trayectoria.

\section{INTRODUÇÃO}

O presente trabalho está inserido em um projeto mais amplo, intitulado "Intérpretes do Maranhão: trajetórias políticas e intelectuais de porta-vozes da 'cultura', da 'política' e da "sociedade"" e desenvolvido no âmbito do Laboratório de Estudos sobre Elites Políticas e Culturais (LEEPOC), vinculado ao Programa de Pós-Graduação em Ciências Sociais da Universidade Federal do Maranhão (UFMA), sob a coordenação dos professores doutores Igor Gastal Grill e Eliana Tavares dos Reis. Nesta pesquisa, o foco se dirige à investigação das condições e dos condicionantes do exercício do trabalho político e intelectual de alguns intérpretes do Maranhão pertencentes ao Instituto Histórico e Geográfico do Maranhão (IHGM), mediante o estudo dos seus perfis e da produção escrita a seu respeito.

São perseguidos os seguintes objetivos no trabalho: 1) apreender as propriedades sociais dos agentes; 2) identificar as formas de intervenção privilegiadas no âmbito da cultura e da política; e 3) examinar os princípios de legitimação e aferição de excelência social ativados nas estratégias de valorização dos membros da instituição.

Com o intuito de alcançar esses objetivos, foi necessário adotarmos alguns métodos de análise, como o uso da prosopografia ou da biografia coletiva (CHARLE, 2006), mediante o recorte dessa população específica pertencente ao Instituto Histórico e Geográfico do Maranhão (IHGM).

A operacionalização da investigação desdobrou-se em duas etapas: 1) a sistematização e a análise de um banco de dados com informações acerca dos agentes origem geográfica, profissão e escolarização dos seus ascendentes, trajeto escolar, carreiras profissionais, publicações (lugares, ênfases, temáticas etc.), cargos administrativos (na universidade e nas burocracias de governos), cargos eletivos e engajamentos diversos (associativistas, sindicais, religiosos, em movimentos sociais etc.); e 2) exame de trajetórias 
de casos exemplares, evidenciando os percursos escolares, culturais e políticos e as interpretações que produziram por meio de produções escritas sobre "temas" e "pautas" com os quais se identificam.

A principal fonte de dados do trabalho foi a revista da própria instituição, organizada por Leopoldo Gil Dulcio Vaz e Telma Bonifácio dos Santos Reinaldo, intitulada "Perfis dos Sócios: Ocupantes de Cadeiras”, publicada no ano de 2013 e disponível na plataforma on-line denominada "ISSUU: Digital Publishing Platform".

\section{ENQUADRAMENTO TEÓRICO}

O recorte temporal abordado nesta pesquisa data do começo dos anos 2000, período em que os sessenta e quatro sócios ocupantes de cadeiras foram empossados, além disso, o foco desta investigação dirige-se às condições e aos fatores condicionantes do exercício do trabalho político e intelectual de sessenta e quatro (64) membros efetivos do Instituto Histórico e Geográfico do Maranhão (IHGM), por intermédio da análise dos perfis desses membros e também de suas produções escritas, e, para tanto, é relevante compreender que o trabalho intelectual e político dos agentes em questão, incluindo a produção de livros, confere a estes posições mais altas nos espaços sociais, como apontado em Grill e Reis (2012, p. 103).

Inicialmente, é necessário debruçar-se sobre o período em que o Instituo Histórico e Geográfico do Maranhão (IHGM) se instaura no estado, e isso ocorre a partir da criação da instituição denominada Instituto Histórico e Geográfico do Brasil (IHGB). Cabe ressaltar, também, que o Instituto Histórico e Geográfico do Brasil (IHGB) advém da importação de instituições congêneres da Europa, chegando ao Brasil no ano de 1839 e sendo considerado uma instituição legítima e oficial no país - portanto, com a finalidade de garantir, sobretudo, uma história nacional "oficial” (SCHWARCZ, 1993).

Também vale salientar que o Instituto Histórico e Geográfico do Maranhão (IHGM) foi fundado em São Luís no dia 20 de novembro de 1925, por Antônio Lopes da Cunha, após a criação do Instituo Histórico e Geográfico do Brasil (IHGB). O instituto foi criado com objetivos específicos, dentre os quais estavam: estudar e divulgar questões sobre História e Geografia do Maranhão, assim como do Brasil; defender o patrimônio histórico do estado; cooperar com os poderes públicos nas medidas em que visem o engrandecimento científico e cultural do estado do Maranhão; promover a coleta de documentos relativos a efemérides; estimular estudos voltados à História e Geografia e ciências afins de todo o país, mas, 
GARCES, K. C. R. Perfis sociais, produção cultural e atuação política dos membros do Instituto Histórico e Geográfico do Maranhão

principalmente, no Maranhão; entre outros (INSTITUTO HISTÓRICO E GEOGRÁFICO DO MARANHÃO, 2007, p. 129-130).

A partir disso, observa-se que o Instituto Histórico e Geográfico do Brasil (IHGB) torna-se a reprodução de um modelo de importação e, também, um modelo para os demais institutos, semelhantes a este, que viriam a ser criados nas configurações regionais do país.

É importante perceber que a forma de seleção dos membros do IHGB não pode ser dissociada da conjuntura histórica vigente no Brasil naquele período. Embora "independente", o Brasil ainda era regido por um imperador, sem que se esqueça das insurgências (revoltas) que ocorriam no país, o que caracterizava, então, o instituto como uma sociedade de corte que produzia uma história nacional a partir de um saber oficial (SCHWARCZ, 1993). Do mesmo modo que o IHGB, o Instituto Histórico e Geográfico do Maranhão (IHGM) torna-se uma instância de consagração e construção de "vultos", afirmando seus membros efetivos como porta-vozes da "cultura", da "política" e da sociedade.

Mediante isso, é imprescindível notar como se estabelece a adaptação desse modelo de instituição importado, construído aos moldes dos centros ocidentais, para espaços na periferia da ordem internacional, observando-se como ocorreram mudanças nas suas funções e significados quando desse deslocamento - exercício semelhante ao realizado por Coradini (2005) ao examinar a Academia Nacional de Medicina, estruturada a partir da Academia Francesa de Medicina.

Além disso, há nesse processo estratégias de importação e exportação de modelos estrangeiros destinadas a hierarquizar as "tradições nacionais", por intermédio das quais percebe-se que os modelos importados são fonte de inspiração para aqueles que jogam no âmbito cultural e político, 'interessados em 'aperfeiçoar', 'modernizar', 'mundializar' ou reinventar instituições, valores, posições etc. de ou em seus países de origem, redefinir o que se joga em suas fronteiras" (REIS, 2013).

Também se faz necessário destacar que em um universo intelectual, cultural e político como esse, as configurações sociais adquirem caráter próprio e passam a caracterizar grupos selecionados, assim como incidem na construção dos "vultos" e, consequentemente, no peso que eles adquirem ao se notabilizarem a partir dessas instâncias de consagração (CORADINI, 1998). Por sua vez, é indispensável notar que os agentes que fazem parte desses grupos e estão dentro desse tipo de instituição possuem posições nos domínios cultural e político e são detentores de recursos culturais, simbólicos e sociais. Sobretudo, é fundamental compreender que os agentes envolvidos nessa construção coletiva de um saber oficial sobre o estado em 
questão, assim como sobre sua imagem, tornam-se, entre outras coisas, uma elite intelectual, capaz de ter voz e peso nos espaços sociais, culturais e políticos nos quais atuam.

Devemos ponderar, ainda, que por representar uma elite intelectual em um estado periférico como o Maranhão, o pertencimento à instituição confere a este grupo meios de dominação, tendo em vista que o Instituto Histórico e Geográfico do Maranhão é produto de uma importação de instituições congêneres da Europa e, portanto, está munido de códigos e estratégias importadas e de poder de imposição diante dos espaços que permeiam a sociedade. Ainda, como pontua Anjos (2002), cabe notar que os intelectuais são mediadores junto aos países centrais e, com isso, apreendem e trazem para o Brasil os códigos ocidentais, dominando-os e, dessa forma, utilizando-os como artifício de dominação.

Além disso, outro aspecto que precisa ser lembrado está pautado na identidade regional e nacional, como ressaltado também por Anjos (2002) É necessário compreender que a identidade pode ser forjada, assim como mudar, se compor e se decompor ao longo do tempo e a qualquer momento - além de também ser artifício de determinadas instituições tidas como legítimas para fortificar e enaltecer uma nuance específica sobre uma "realidade social".

Com efeito, também é importante salientar, como se observa em Pollack (1992), o enquadramento da memória e como ela deve ser compreendida. É preciso, sobretudo, entendê-la como um fenômeno coletivo e social, e não somente como um fenômeno individual. Além do mais, a memória nacional caminha juntamente com a memória coletiva, visto que as datas oficiais advêm das estruturas do jogo político. Mediante isso, não se pode esquecer que a memória nacional representa objeto de disputas importantes.

Em decorrência disso, é relevante compreender que a memória é um fenômeno construído social e individualmente, assim como a identidade — isto é, a memória é um elemento que integra a identidade, que a compõe, e, portanto, a identidade é fundamental para o sentimento de continuidade e coerência de uma pessoa ou coletividade. Outro ponto também importante que se deve lembrar, como pontua Pollack (1992, p. 204-205), é que a disputa existe em torno da memória e da identidade:

A construção da identidade é um fenômeno que se produz em referência aos outros, em referência aos critérios de aceitabilidade, de admissibilidade, de credibilidade, e que se faz por meio da negociação direta com outros. Vale dizer que memória e identidade podem perfeitamente ser negociadas, e não são fenômenos que devam ser compreendidos como essências de uma pessoa ou de um grupo. Se é possível o confronto entre a memória individual e a memória dos outros, isso mostra que a memória e a identidade são valores disputados em conflitos sociais e intergrupais, e particularmente em conflitos que opõem grupos políticos diversos. 
GARCES, K. C. R. Perfis sociais, produção cultural e atuação política dos membros do Instituto Histórico e Geográfico do Maranhão

Outro aspecto relevante neste tipo de instituição é que existe a predominância da unidade, de discursos específicos que aproximam seus membros, de mecanismos informais de admissão etc. Deve-se averiguar, como lembra Quintella (1984), a complexidade das formas e mecanismos que fazem com que esta unidade aconteça. Um desses mecanismos reside na presença simultânea de membros de um determinado grupo em diferentes instâncias de consagração. A homogeneidade advém, portanto, do monopólio das posições e da cumplicidade de valores comuns a uma elite que se impõe em vários espaços de poder cultural (QUINTELLA, 1984, p.118).

\begin{abstract}
Acreditamos ser verdadeiro que é um grupo só sobrevive e marca influencia na sociedade abrangente na medida em que seus membros se solidarizam enquanto unidade e, no confronto com outros grupos, as possíveis divergências internas cedem lugar a uma homogeneidade que se afiguraria, então, dominante.
\end{abstract}

Há também uma regularidade de características e qualidades presentes nos membros que ingressam nestes tipos de instituição, uma vez que esses atributos se tornam o alicerce da homogeneidade do grupo (QUINTELLA, 1984). Como grifado por Grill e Reis (2016, p. 4), em seu estudo sobre "Intérpretes e notáveis da literatura e da cultura popular no Maranhão", existe um sentimento de unidade e coesão nesses grupos específicos que propicia essa construção da uniformidade:

Seus membros estão presentes em outras instâncias (culturais e políticas) e/ou interligam-se, por laços pessoais ou familiares, com agentes muito bem situados no espaço do poder estadual.

Assim, como o Instituo Histórico e Geográfico do Maranhão (IHGM) se insere também nesse molde de instância de consagração, é possível notar a predominância dos membros do instituto em outras instituições, como a Academia Maranhense de Letras e a Academia Maranhense de Ciências. Em decorrência disso, outra questão que precisa ser ressaltada se refere às formas de seleção dos agentes dessas instâncias de consagração. Como visto por Coradini (2005) na Academia Nacional de Medicina, há princípios de recrutamento para a entrada dos novos membros em instituições que se responsabilizam pela edificação de "panteões", cujos critérios de legitimação são o parentesco, as redes de reciprocidade, os vínculos políticos e uma definição de cultura "aristocrática e imanentista". Tal configuração pode ser vista também em Grill e Reis (2016, p. 17), já mencionados anteriormente, no que diz respeito às formas de seleção de agentes ligadas às redes, aos vínculos e às relações pessoalizadas que estes constroem e mantêm: 


\begin{abstract}
Há entre os participantes do empreendimento pelo menos mais 08 casos de relações de parentesco, ao que é somado o pertencimento - igualmente preponderante e há bastante tempo - ao mesmo círculo de amizade e as inscrições nos mesmos domínios culturais. A esses vínculos, são acrescidos outros, por exemplo, derivados da conexão dos agentes com a universidade. Mediante laços de orientação, professores renovam adesões de jovens pesquisadores com perfis e engajamentos homólogos na "cultura popular" do estado. E alguns deles encontram disponibilidade de publicar artigos em um veículo como o Boletim da CMF e outros passam efetivamente a compor essa instância. É claro que isso não significa cálculo instrumental, pelo contrário, verifica-se a existência de uma matriz de referências comuns que animam relações e inserções sinceras.
\end{abstract}

Como visto anteriormente, aqueles que pleiteiam ser aceitos nessas instâncias de consagração devem, sobretudo, possuir determinadas qualidades ou características, que permeiam também aqueles já considerados consagrados na instituição, como os membros fundadores, patronos e ascendentes nas cadeiras.

Além disso, há uma hierarquização interna dentro do IHGB, recorrente nas demais instituições regionais, como se observa inclusive no Instituto Histórico e Geográfico do Maranhão (IHGM) — vendo-se, a partir da análise do estatuto em voga da instituição, a existência de subdivisões entre os sócios, sendo uns responsáveis por funções ditas "figurativas" e outros por funções mais trabalhosas (SCHWARCZ, 1993).

Outro aspecto necessário a ser compreendido, por fim, está relacionado à produção de livros dos membros em questão, que pode ser tomada como uma produção intelectual desses agentes, visto que está ligada, sobretudo, a posições alcançadas por eles nos domínios em que atuam. Cabe notar, igualmente, que a escrita está situada dentre as produções de bens simbólicos e é considerada um bem bastante legítimo (GRILL; REIS, 2012).

Em suma, além do que foi levantado, vale salientar que a atividade da escrita nos espaços públicos concede a estes agentes estratégias para se tornarem cada vez mais legítimos, pois, "instituindo representações através dos escritos, os porta-vozes podem se reestabelecer como representantes legítimos, balizando sua singularidade", como se observa em Grill e Reis (2012, p. 106). Ainda, é necessário compreender também que há imbricações entre os domínios sociais que precisam ser levadas em consideração quando se observa o universo intelectual e político dos agentes em questão. 
GARCES, K. C. R. Perfis sociais, produção cultural e atuação política dos membros do Instituto Histórico e Geográfico do Maranhão

\section{PERFIS SOCIAIS, PRODUÇÃO CULTURAL E ATUAÇÃO POLÍTICA DOS MEMBROS DO INSTITUTO HISTÓRICO E GEOGRÁFICO DO MARANHÃO (IHGM)}

Esta seção tem o intuito de demonstrar, através dos gráficos a seguir, a composição sociográfica dos sessenta e quatro (64) membros efetivos do Instituto Histórico e Geográfico do Maranhão (IHGM). Necessário mencionar também que todas as informações contidas nos gráficos foram retiradas da própria revista do IHGM, "Perfis dos Sócios: Ocupantes de Cadeiras", publicada no ano de 2013 e disponível na plataforma on-line denominada "ISSUU: Digital Publishing Platform".

No que tange os procedimentos metodológicos da pesquisa adotamos o uso da biografia coletiva ou método prosopográfico (CHARLE, 2006), por essa técnica possibilitar um escrutínio sobre determinados grupos sociais. O uso do método consiste na construção de um quadro que nos indica certas características comuns de determinadas coletividades, assim como releva as dinâmicas desses grupos.

Dessa forma, os gráficos foram construídos por intermédio do banco de dados construído com variáveis consideradas relevantes ao método (origens sociais, percursos escolares e acadêmicos, inscrições culturais e políticas e livros publicados) para a análise da composição do grupo em questão. E, na sequência, analisamos por meio de frequências as similaridades e particulares dessa população específica.

GRÁFICO 1 - LOCAL DE NASCIMENTO

\begin{tabular}{|c|c|c|}
\hline $22,22 \%$ & $55,55 \%$ & $20 \%$ \\
\hline São Luís (MA) & $\begin{array}{c}\text { Cidades do interior (MA) } \\
\square \text { Local de Nascimento }\end{array}$ & Outros estados \\
\hline
\end{tabular}

FONTE: REVISTA DO INSTITUTO HISTÓRICO E GEOGRÁFICO DO MARANHÃO (2013, pg.54-186).

No gráfico acima percebe-se que mais da metade dos agentes do IHGM são naturais do Maranhão. Como visto no gráfico, 55,55\% deles são de cidades do interior do estado do Maranhão, como Tutóia, São Bento, Pedreiras, Timon etc. 22,22\% são da capital do estado (São Luís) e $20 \%$ são naturais de outros estados, como São Paulo, Rio de Janeiro, Ceará e Piauí. Em relação ao gráfico, observa-se que mais da metade dos agentes que compõem esse 
grupo advêm de cidades do interior do estado do Maranhão, e que a maioria deles é natural do Maranhão.

\section{GRÁFICO 2 - INSTITUIÇÃO DE CONCLUSÃO DO ENSINO MÉDIO}

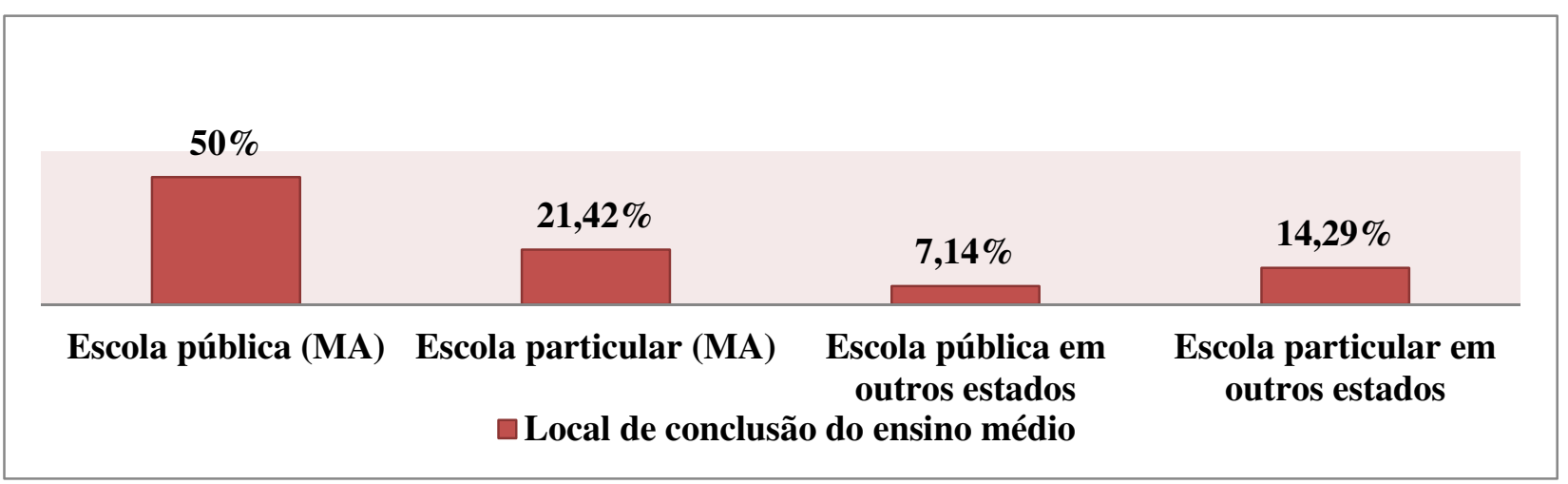

FONTE: REVISTA DO INSTITUTO HISTÓRICO E GEOGRÁFICO DO MARANHÃO (2013, pg.54-186.)

A partir do gráfico acima, observa-se que 50\% dos agentes do IHGM concluíram o Ensino Médio em instituições públicas do estado do Maranhão. Observa-se, também, que essas instituições estão, majoritariamente, localizadas na capital do estado (São Luís), sendo exemplos de tais escolas o Liceu Maranhense e o Centro de Ensino Médio Almirante Tamandaré. A seguir, 21,42\% dos agentes concluíram o ensino médio em instituições privadas na capital do Maranhão, como o Colégio Santa Teresa, o Colégio Batista e o Colégio Dom Bosco. 7,14\% dos agentes estudaram nas escolas públicas em outros estados, como visto no gráfico, estando dentre essas escolas o Colégio Elefante Branco em Brasília. No que tange às instituições privadas em outros estados - como o Colégio Princesa Isabel, no Rio de Janeiro - observa-se que 14,29\% dos agentes concluíram o ensino médio neste tipo de instituição.

A partir disso, percebe-se que, embora os membros do Instituto sejam majoritariamente de cidades do interior do Maranhão, suas famílias possuíam condição financeira para enviarem seus filhos para estudar nas escolas da capital do estado, fossem elas públicas ou privadas, assim como para enviá-los para outros estados do Brasil. 
GARCES, K. C. R. Perfis sociais, produção cultural e atuação política dos membros do Instituto Histórico e Geográfico do Maranhão

GRÁFICO 3 - ÁREAS DE CONHECIMENTO NO CURSO DE GRADUAÇÃO ${ }^{4}$

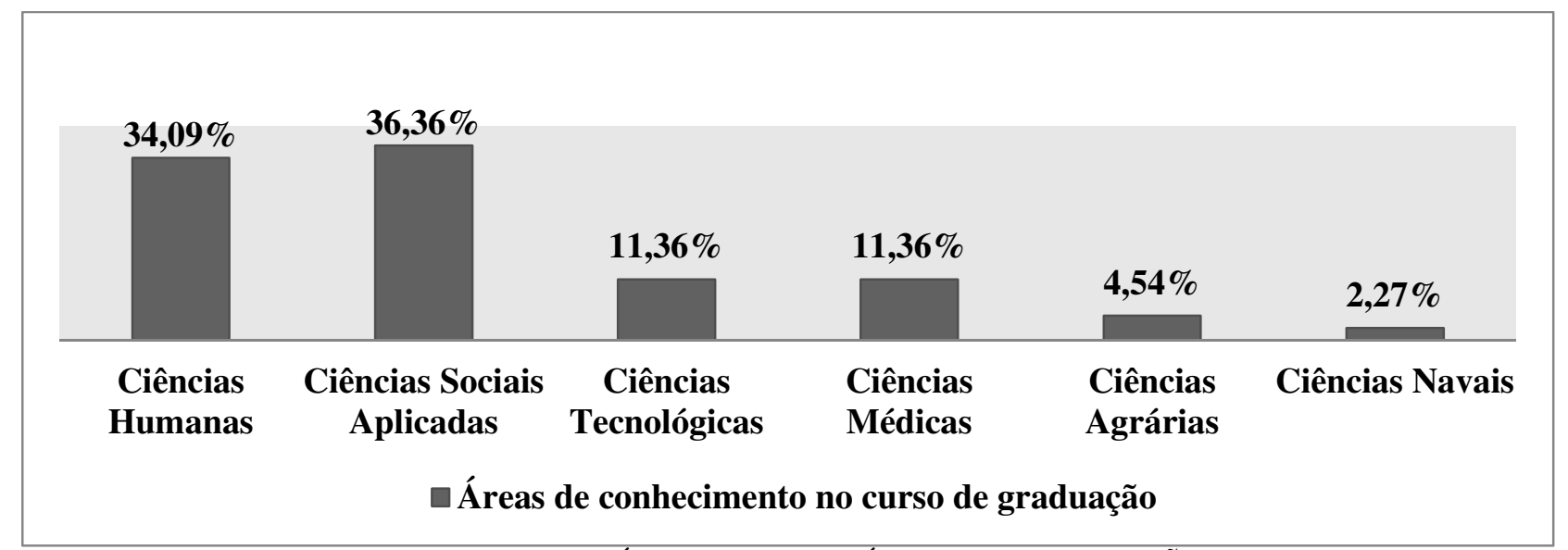

FONTE: REVISTA DO INSTITUTO HISTÓRICO E GEOGRÁFICO DO MARANHÃO (2013, pg.54-186).

É importante deixar claro que dos 64 agentes pesquisados na Revista do IHGM somente 48 agentes trazem em seus perfis a informação sobre o curso de graduação. No entanto, embora os 16 agentes restantes não mencionem está variável, não significa que estes não possuem curso de graduação.

A partir disso, nota-se que a área de conhecimento de mais peso dentre as escolhas dos agentes referentes à graduação é a de Ciências Sociais Aplicadas — como Direito (a maior parte), Pedagogia, Comunicação Social e Administração —, com 36,36\% dos agentes. É importante ressaltar que o número de agentes do sexo masculino nessa área de conhecimento é predominante.

Em segundo lugar, com 34,09\%, está a área de Ciências Humanas, englobando cursos como Ciências Sociais, Geografia, História, Psicologia, Letras e Teatro. Os números não são muito diferentes dos de Ciências Sociais Aplicadas e, nesse universo, percebe-se que, diferentemente do que ocorre com as Ciências Sociais Aplicadas ${ }^{5}$ que englobam cursos como Direito, Economia, Administração, Jornalismo, entre outros (ver nota de rodapé), os agentes do sexo feminino predominam.

Já as áreas de Ciências Tecnológicas e Ciências Médicas somam 11,36\%. A primeira abarca cursos como Engenharia Elétrica, Engenharia Civil e Arquitetura, e a segunda, cursos como Medicina Veterinária e Medicina. Ambas as áreas de conhecimento são dominadas por agentes do sexo masculino.

\footnotetext{
4 As porcentagens foram calculadas sobre o total de agentes em relação aos quais conseguimos obter informações, e não sobre o total de agentes do Instituto.

5 O termo "Ciências Sociais Aplicadas" refere-se a uma das áreas de conhecimento científico, aqui não abordamos nenhum recorte histórico. O termo serve para situar a preferência dos membros em questão dentro dos cursos acadêmicos.
} 
Por fim, nas Ciências Agrárias, com 4,54\%, e nas Ciências Navais, com 2,27\%, não constam agentes do sexo feminino. Tanto nas primeiras quanto nas últimas áreas de conhecimento, o número de agentes do sexo masculino é predominante.

GRÁFICO 4 - INSTITUIÇÕES DE CONCLUSÃO DO CURSO DE GRADUAÇÃO

$\square$ Instituição de conclusão do curso de graduação

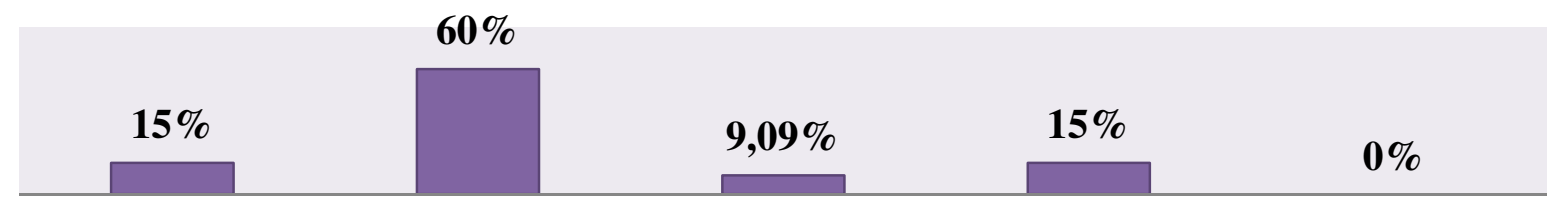

\section{Particular (MA) $\quad$ Pública (MA) $\quad$ Particular em $\quad$ Pública em $\quad$ Outro país outros estados outros estados}

FONTE: REVISTA DO INSTITUTO HISTÓRICO E GEOGRÁFICO DO MARANHÃO (2013, pg.54-186).

Quanto às informações referentes às instituições em que os agentes concluíram o curso de graduação, observa-se que $60 \%$ deles o fizeram em instituições públicas de ensino superior do estado do Maranhão. 15\% concluíram o curso superior em instituições privadas de ensino superior no Maranhão, e também 15\% em instituições públicas de ensino superior em outros estados. 9,09\% concluíram a graduação em faculdades particulares em outros estados.

GRÁFICO 5 - ÁREA DE CONHECIMENTO DO MESTRADO

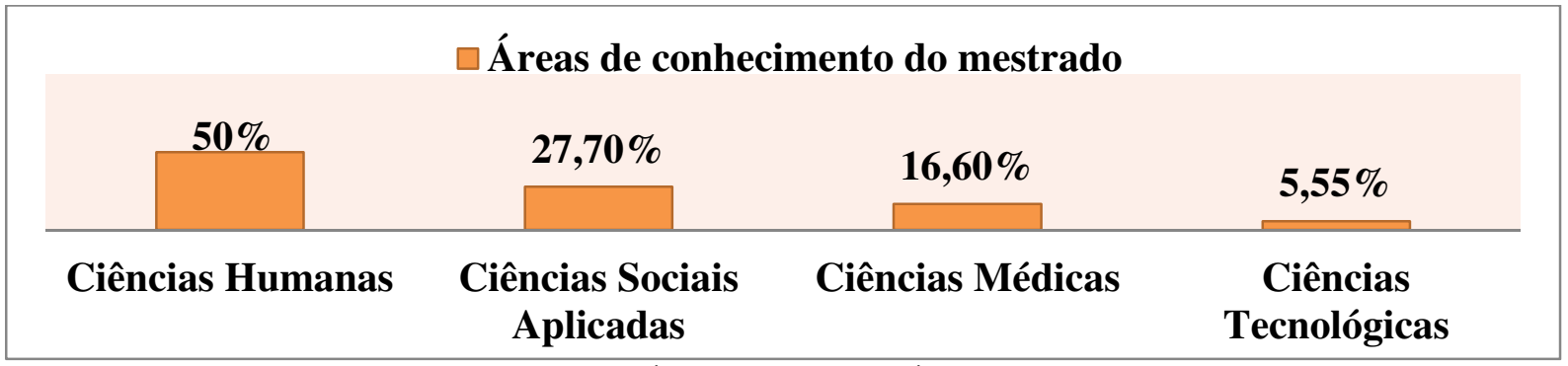

FONTE: REVISTA DO INSTITUTO HISTÓRICO E GEOGRÁFICO DO MARANHÃO (2013, pg.54-186).

Faz-se necessário grifar que dos 64 agentes pesquisados na Revista do IHGM somente 19 agentes trazem em seus perfis a informação sobre o título de mestrado.

Dentre as áreas do mestrado, a que fica mais em evidência é a área de Humanas, com $50 \%$ dos agentes, na qual predominam os homens. Em segundo lugar, com 27,7\%, está a área de Ciências Sociais aplicadas. Aqui, novamente predominam os homens. Em terceiro lugar, com 16,6\%, estão as Ciências Médicas, e, finalmente, em quarto lugar, as Ciências Tecnológicas, com 5,5\%. Ambas as áreas são majoritariamente dominadas por agentes do sexo masculino. 
GARCES, K. C. R. Perfis sociais, produção cultural e atuação política dos membros do Instituto Histórico e Geográfico do Maranhão

GRÁFICO 6 - INSTITUIÇÃO DE CONCLUSÃO DO MESTRADO

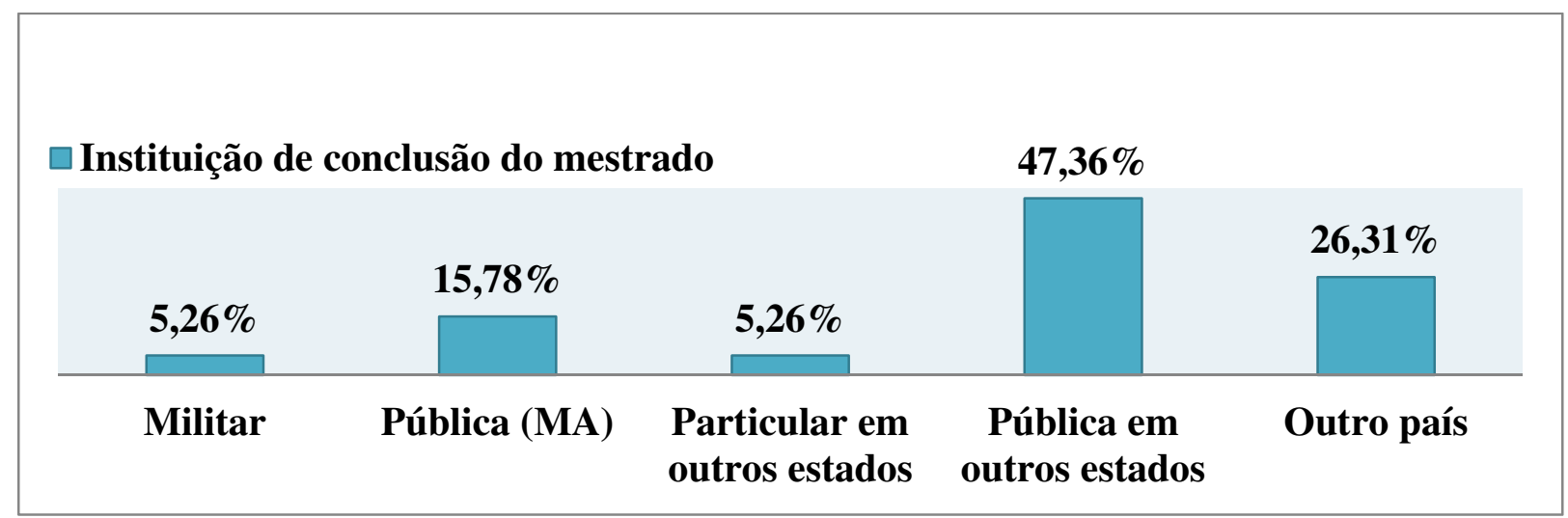

FONTE: REVISTA DO INSTITUTO HISTÓRICO E GEOGRÁFICO DO MARANHÃO (2013, pg.54-186).

A partir do gráfico acima, percebe-se que as instituições em que foram concluídos os mestrados dos agentes são, sobretudo, instituições de ensino público localizadas em outros estados (47,36\%). Em seguida, com 26,31\%, vêm as universidades fora do Brasil. Em terceiro lugar, com 15,78\%, estão as instituições públicas do estado do Maranhão, como a UFMA e Universidade Estadual do Maranhão (UEMA). Dentre as demais instituições, estão as particulares em outros estados, com 5,26\%, e as instituições militares, como a Escola de Guerra Naval, no Rio de Janeiro, com a mesma porcentagem.

Nota-se que um número considerável dos agentes analisados concluiu o mestrado em instituições fora do país. É importante observar que isso soma em notabilidade para esses agentes, já que adquirir conhecimento em outros países, principalmente em países centrais, como a França e a Bélgica, além de países do continente Latino-Americano, como a Colômbia e Cuba, tornam estes agentes membros diferenciados entre seus pares.

\section{GRÁFICO 7 - ÁREA DE CONHECIMENTO DO DOUTORADO}

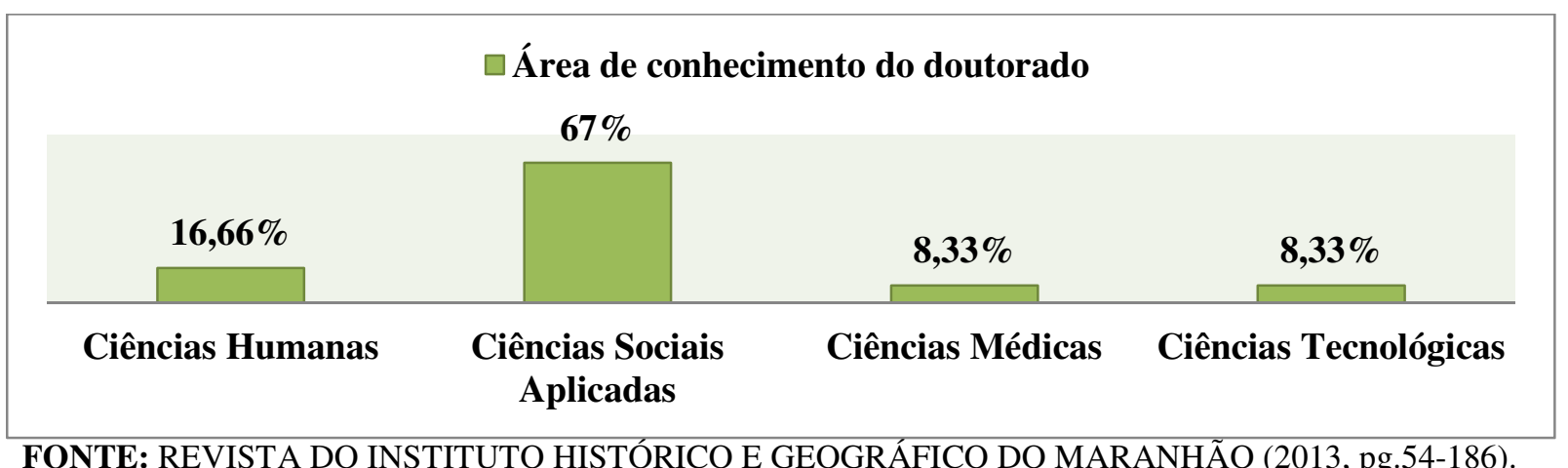

É importante pontuar que dos 64 agentes pesquisados na Revista do IHGM somente 14 agentes trazem em seus perfis a informação sobre o título de doutorado. 
Dentre as áreas do doutorado, em primeiro lugar estão as Ciências Sociais Aplicadas, com $67 \%$ dos agentes, diferentemente do gráfico referente ao mestrado. Aqui, há a predominância de mulheres. Em segundo lugar, com 16,66\%, estão as Ciências Humanas, onde há majoritariamente agentes do sexo masculino, e em terceiro e quarto lugares as Ciências Médicas e Ciências Tecnológicas, ambas com 8,33\%. Nestas áreas também há a predominância de agentes do sexo masculino.

\section{GRÁFICO 8 - INSTITUIÇÃO DE CONCLUSÃO DO DOUTORADO}

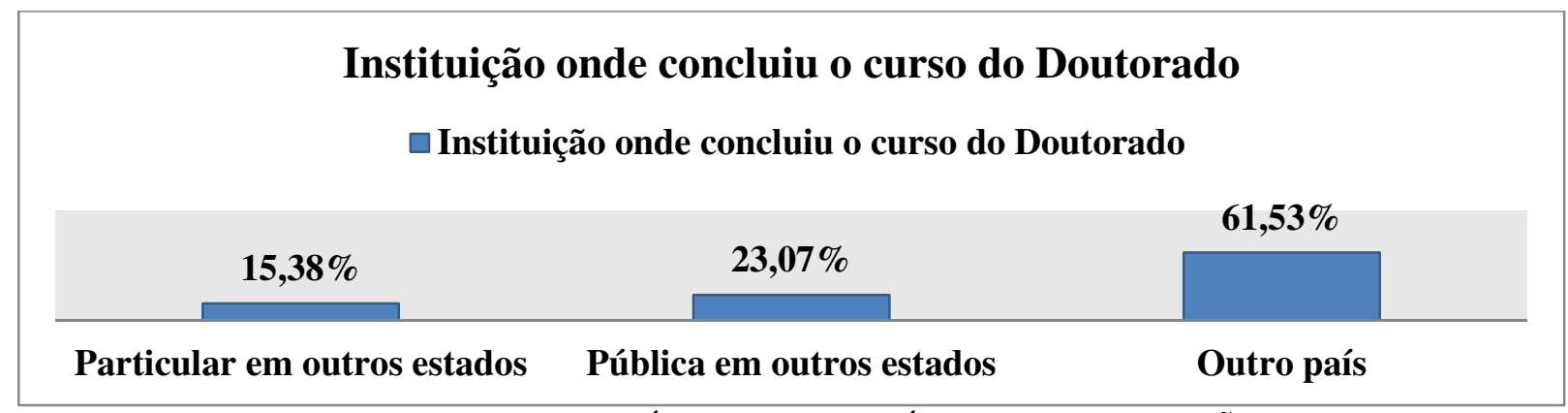

FONTE: REVISTA DO INSTITUTO HISTÓRICO E GEOGRÁFICO DO MARANHÃO (2013, pg.54-186).

No gráfico acima nota-se que $61,53 \%$ dos agentes concluíram o doutorado em instituições fora do Brasil. As instituições públicas em outros estados somam 23,07\%, enquanto 15,38\% dos agentes cursaram o doutorado em instituições particulares de outros estados.

As instituições de ensino público e privado localizadas no estado do Maranhão não foram encontradas na fonte pesquisada, o que mostra, por um lado, a formação tardia dos doutorados no Maranhão e, por outro, os recursos de que dispõem os agentes para circular pelo país ou pelo mundo investindo em títulos educacionais.

Em relação aos artigos publicados pelos agentes do Instituto, percebe-se que em 70\% dos casos não havia informações sobre esta variável na fonte pesquisada. Dentre os $30 \%$ que registraram esse tipo de produção, constavam artigos voltados ao meio jurídico e a outras áreas, como Ciência Médica e Artes Plásticas. Também eram mencionados, entre outros, artigos sobre patrimônio cultural e artigos históricos.

A partir das informações coletadas da fonte pesquisada, verificou-se que esses artigos foram publicados em revistas científicas, revistas especializadas, jornais locais e, também, jornais de alcance nacional e internacional. Além disso, há artigos publicados na própria revista da instituição. 
GARCES, K. C. R. Perfis sociais, produção cultural e atuação política dos membros do Instituto Histórico e Geográfico do Maranhão

Em relação a variável sobre os projetos criados ou coordenados pelos agentes em questão, nota-se que estes projetos estão ligados, principalmente, ao âmbito da cultura e no âmbito educacional, entre outros. Em $76 \%$ dos casos não foi encontrado nenhum tipo de informação na fonte de pesquisa a esse respeito, o que não significa que tais agentes não tenham efetivamente coordenado nenhum projeto. Em somente $24 \%$ dos casos foram apresentadas informações sobre esses projetos, dentre os quais estão projetos voltados para a educação básica, a qualificação de docentes, a residência médica, a pesquisa de extensão referente à área médica, a cultura e a arte — tendo eles, portanto, objetivos diversos.

Em relação aos engajamentos militantes, observa-se que somente $8 \%$ dos agentes fazem menção a estas inscrições. Constam envolvimentos com grêmios estudantis, com o movimento negro, com movimentos sindicais, entre outros. Tal vínculo é predominante em agentes da área de Ciências Humanas.

GRÁFICO 12 - CARGOS ADMINISTRATIVOS CONQUISTADOS EM UNIVERSIDADES

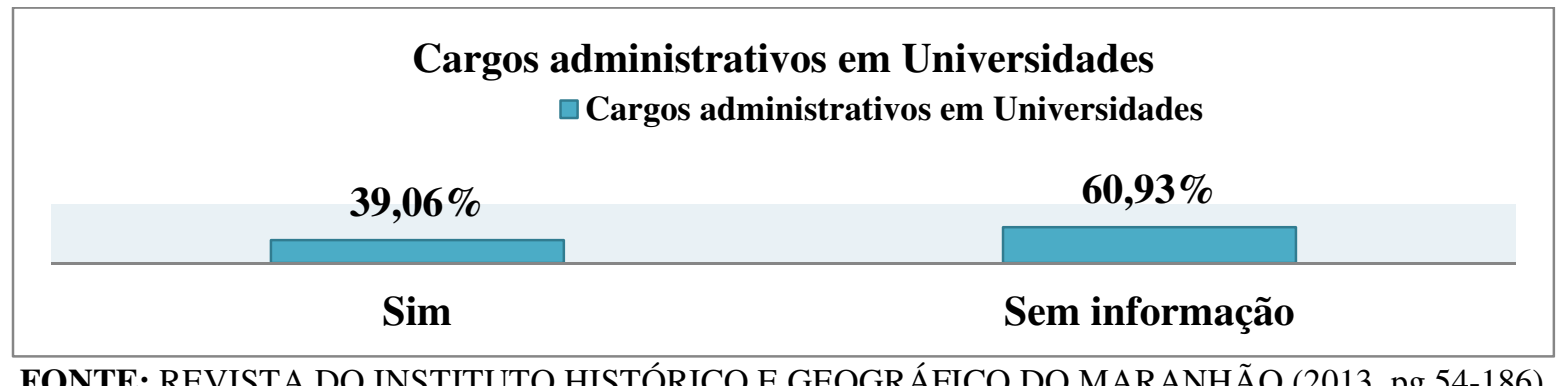

A partir do gráfico acima, percebe-se que 39\% dos agentes ocuparam cargos no âmbito das universidades. Foram coordenadores de cursos, reitores, pró-reitores e presidentes de conselhos superiores (como CONSUN e CONSEPE), além de diretores e vice-diretores de faculdades, assessores de reitorias etc. São, no total, vinte e cinco (25) os agentes que no gráfico representam estes 39\%, enquanto trinta e nove (39) agentes contabilizam os $61 \%$ que, como visto no gráfico, não tem tais cargos registrados na fonte pesquisada - o que não significa que não tenham necessariamente ocupado esses cargos 
GRÁFICO 13 - CARGOS ADMINISTRATIVOS NO PODER PÚBLICO

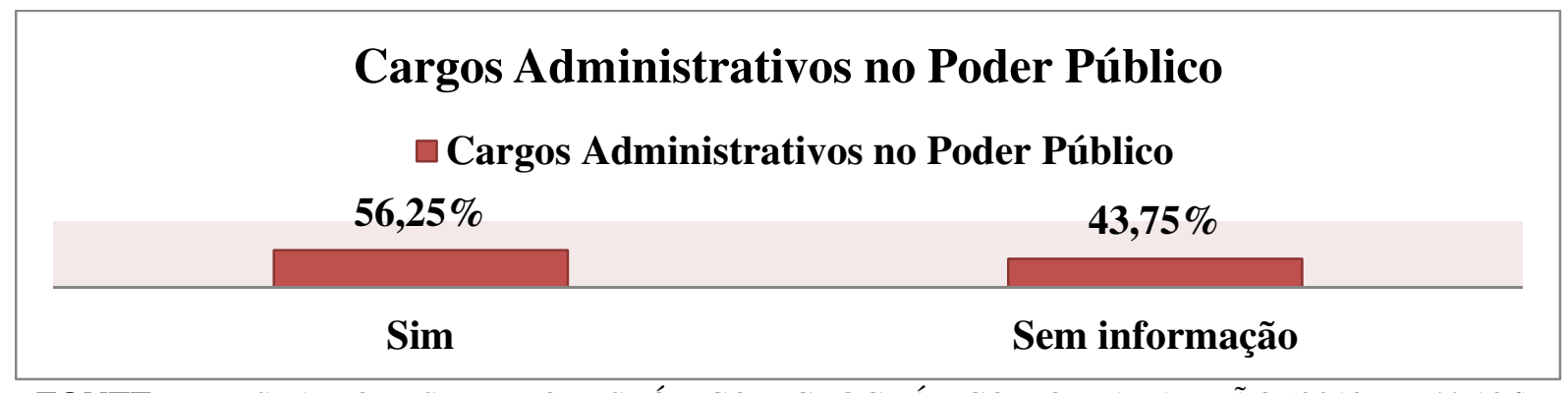

FONTE: REVISTA DO INSTITUTO HISTÓRICO E GEOGRÁFICO DO MARANHÃO (2013, pg.54-186).

56\% dos agentes ocuparam cargos administrativos no poder público, como cargos em Ministérios (Agricultura, Saúde, Cultura, Fazenda, entre outros), cargos com função de direção em Departamentos (Estadual de trânsito, Agropecuária etc.) e cargos com função de secretários(as) (de Cultura, Educação, Esporte, entre outros), assim como cargos de assessores(as) e conselheiros(as).

No total foram encontradas informações referentes a trinta e seis (36) agentes, enquanto não há, na fonte pesquisada, dados a respeito de $44 \%$ dos agentes (o que não quer dizer que eles não tenham ocupado esses cargos).

\section{GRÁFICO 14 - CARGOS ELETIVOS OCUPADOS}

\begin{tabular}{|c|c|}
\hline \multicolumn{2}{|c|}{ Cargos Eletivos Ocupados } \\
\hline $4,68 \%$ & $95,31 \%$ \\
\hline Sim & m informação \\
\hline
\end{tabular}

FONTE: REVISTA DO INSTITUTO HISTÓRICO E GEOGRÁFICO DO MARANHÃO (2013, pg.54-186).

Mediante a análise do gráfico acima, nota-se que somente 5\% dos agentes conquistaram cargos eletivos - ou seja, foram encontrados somente três (3) agentes dentre os sessenta e quatro (64) com essa característica.

Essa quase ausência dos membros do IGHM em cargos eletivos pode ser compreendida como a predominância dos mesmos em outras atividades, como a da escrita e, principalmente, a ocupação de cargos no poder público e nas burocracias universitárias.

No que se refere à participação em outras instâncias de consagração, além de serem membros efetivos do IHGM, observamos que 50\% dos agentes participavam de grupos como a Academia Arariense-Vitoriense de Letras, o Conselho Estadual de Cultura do Maranhão, a 
GARCES, K. C. R. Perfis sociais, produção cultural e atuação política dos membros do Instituto Histórico e Geográfico do Maranhão

Sociedade Brasileira de Nefrologia, o Conselho Curador da Fundação Antônio Jorge Dino, a Academia Maranhense de Letras, a Academia Maranhense de Ciência, a Academia Maranhense de Letras Jurídicas e a Sociedade Brasileira para o Progresso da Ciência (SBPC).

Em relação aos outros 50\%, não há informações na fonte pesquisada (o que, novamente, não significa que tais agentes não tenham participado de outras instâncias de consagração).

GRÁFICO 16 - LIVROS PUBLICADOS

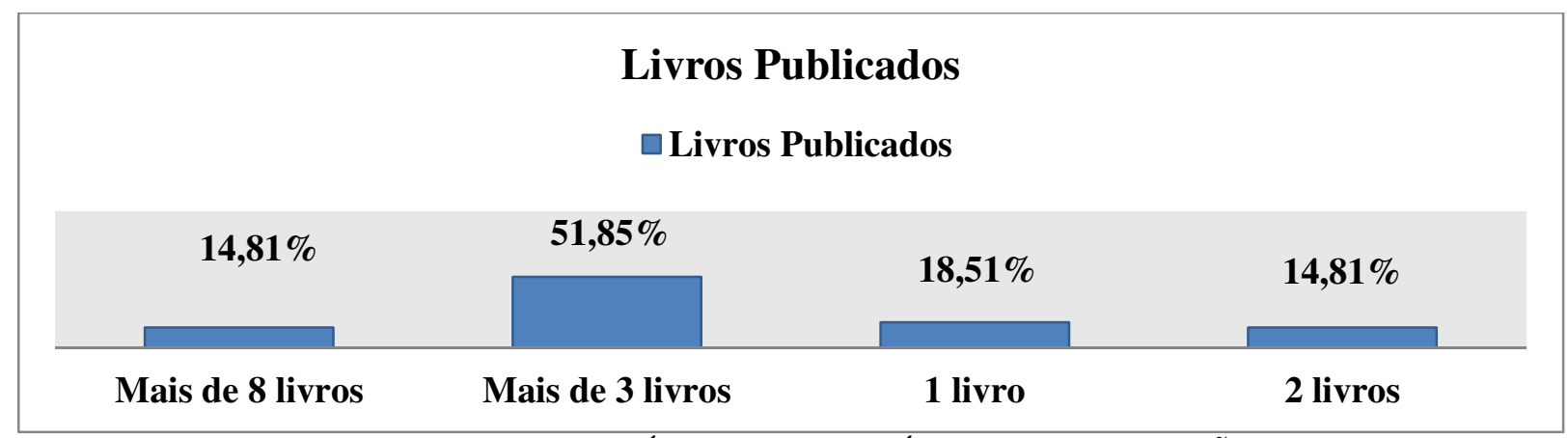

FONTE: REVISTA DO INSTITUTO HISTÓRICO E GEOGRÁFICO DO MARANHÃO (2013, pg.54-186).

Por meio das informações do gráfico nota-se que entre os sessenta e quatro (64) agentes analisados, foram encontrados vinte e sete (27) com publicação de livros - com destaque para os quatorze (14) agentes com mais de três livros publicados, de gêneros diversos: contos, poesias, crônicas, biográficos etc. Os outros agentes que se destacam são os cinco (5) que publicaram até um livro, também distribuídos em gêneros diversos. A porcentagem daqueles que publicaram mais de oito livros e até dois livros é de $15 \%$ cada.

GRÁFICO 17 - PRÊMIOS CONQUISTADOS

Prêmios consquistados Prêmios consquistados

\begin{tabular}{cc}
$32,81 \%$ & $67,18 \%$ \\
\hline Sim & Sem informação \\
\hline
\end{tabular}

FONTE: REVISTA DO INSTITUTO HISTÓRICO E GEOGRÁFICO DO MARANHÃO (2013, pg.54-186).

A partir do gráfico acima, percebe-se que 33\% dos agentes em questão conquistaram prêmios concedidos por poderes públicos e instâncias culturais. Esses prêmios vão desde medalhas de mérito, títulos de cidadania e menções honrosas à distinção honorífica em universidades. É necessário compreender que esse tipo de honraria assume um papel importante no acúmulo de capital simbólico de tais agentes. 
GRÁFICO 18 - ESTÁGIOS NO EXTERIOR

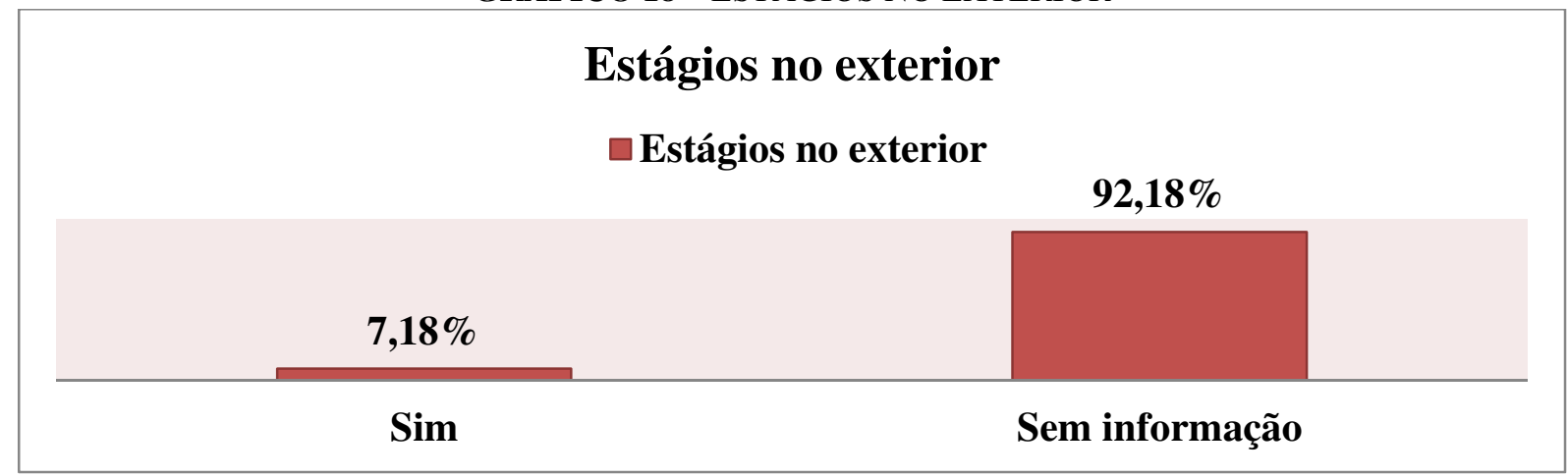

FONTE: REVISTA DO INSTITUTO HISTÓRICO E GEOGRÁFICO DO MARANHÃO (2013, pg.54-186).

Dentre os sessenta e quatro (64) agentes analisados, só foram encontradas informações, em relação a essa variável, referentes a cinco (5) agentes, com estágios em diversos países e em diferentes instituições - como se vê, por exemplo, nas informações sobre um deles: especialização na área de energia no Department of Energy, em Londres, em 1981; Spirax Sarco, em Chelteham, também em 1981; Nova Scotia Power Plant, em Hallifaz, em 1988; e Energy Management Course e Fabrimeal, em Bruxelas, entre outubro e novembro de 1989.

\section{PERFIS DE MEMBROS EFETIVOS DO IHGM}

Mediante as informações coletadas sobre os sessenta e quatro membros do IHGM, selecionamos alguns agentes que se destacaram entre os demais membros da instituição. São três agentes que se enquadram nas regularidades observadas nos quadros prosopográficos, no que tange às suas características sociais, mas que apresentam a particularidade de apresentarem uma forte inserção no domínio político-eleitoral. Ademais, configuram um grupo de intérpretes do Maranhão. São eles: Joaquim Elias Nagib Pinto Haickel, José Jorge Leite Soares e Washington Luiz Maciel Cantanhede.

Além disso, em vista dos argumentos apresentados, no que concerne ao perfil de alguns intérpretes do Maranhão — os membros efetivos do Instituto Histórico e Geográfico do Maranhão (IHGM) —, nota-se que tais agentes possuem um acúmulo de recursos diversos e multidimensionais que os auxiliam, sobretudo, a subir de posição dentro da pirâmide social.

Esses recursos podem ser observados nos títulos escolares, em postos conquistados em esferas do poder público e dentro de domínios acadêmicos, nos cargos eletivos e na atividade da escrita de tais intérpretes. Cabe notar que todos esses recursos se configuram em estratégias utilizadas por um grupo dominante. No que se refere a esses atributos, é possível 
GARCES, K. C. R. Perfis sociais, produção cultural e atuação política dos membros do Instituto Histórico e Geográfico do Maranhão

notar que os agentes do Instituto Histórico e Geográfico do Maranhão ocupam em número considerável cargos no poder público, como visto em um dos gráficos apresentados (cerca de $60 \%$ dos casos). Com relação aos cargos ocupados em burocracias universitárias, no entanto, o gráfico é diverso, pois observamos tal configuração em somente cerca de $40 \%$ dos casos. No que diz respeito aos cargos eletivos ocupados, somente em $5 \%$ dos casos é mencionada a ocupação de cargos como vereador, deputado federal e deputado estadual, o que, em relação às duas variáveis anteriores, é um número bem inferior.

No que diz respeito aos títulos escolares, é importante lembrar que a conclusão do ensino médio foi efetivada por tais agentes, majoritariamente, em instituições de ensino público do estado do Maranhão (50\%), enquanto os cursos de graduação foram por eles concluídos, principalmente, em universidades públicas do Maranhão (60\%). No que se refere ao mestrado, os locais de conclusão foram majoritariamente universidades públicas em outros estados $(47,36 \%)$ e universidades fora do Brasil (26,31\%), e os doutorados foram feitos, principalmente, em universidades fora do país (61,53\%). Diante disso, observa-se que a relevância de estudar fora do país, no que tange ao maior título, confere mais um diferencial a esses agentes dentre os seus pares. Ainda, deve-se perceber que a presença das agentes do sexo feminino (vale salientar que dos 64 membros analisados, 18 são agentes do sexo feminino e 46 agentes são do sexo masculino) nos cursos acima listados, com relação ao número de agentes masculinos, é majoritariamente menor. Isso se dá por diversos fatores, e entre eles poderiam ser elencadas as problemáticas que giram em torno das questões de gênero no país.

Em relação à presença desses membros do IHGM em outras instâncias de consagração, nota-se que em 50\% dos casos se faz menção à participação dos agentes em outros institutos ou academias. Deve-se mencionar que isso está relacionado à necessidade de homogeneidade de um grupo, pois é a partir de um caráter homogêneo que se configura um grupo dominante.

Quanto aos livros publicados, observa-se que 52\% dos agentes publicaram mais de três livros; $15 \%$ publicaram mais de oito livros, e também 15\% tiveram até dois livros publicados. Por fim, $18 \%$ dos intérpretes tiveram até um livro publicado. Sobre essa atividade da escrita e da publicação de livros, cumpre lembrar que esse tipo de exercício confere legitimidade aos agentes e que, como visto em Grill e Reis (2012), "com efeito, a 'arte de representar' e a 'arte de escrever' encontram-se imbricadas e, possivelmente, compõem um princípio organizador das práticas que se impõem gerando efeitos, mesmo que frágeis, de refração para o espaço político". 
Em relação aos prêmios conquistados, nota-se que em 21 casos são mencionados medalhas de mérito, títulos de cidadania, menções honrosas concedidas por instituições de governo e universidades, concursos literários, entre outros. Isso se configura em bens simbólicos.

No que se refere aos locais de origem dos intérpretes, observa-se que 55,55\% deles são de cidades do interior do estado do Maranhão, enquanto 22,22\% são da capital do estado e $20 \%$ provêm de outros estados - ou seja, os agentes são majoritariamente maranhenses, o que confere uma regularidade entre eles.

Assim, faz-se necessário compreender que há imbricações relevantes nos espaços políticos e culturais e, principalmente, no espaço que confere legitimidade aos indivíduos no universo intelectual. Todos esses espaços se encontram ligados, assim como as disputas que ocorrem em face da busca de posições mais elevadas entre os agentes que compõem esses espaços. A partir disso, verifica-se que esses agentes, com função de porta-vozes ou de intérpretes da sociedade, se afirmam, sobretudo, a partir de atuações em instâncias de consagração, que, como vimos, possuem critérios e requisitos de admissão que promovem uma coesão ideológica.

O quadro abaixo aponta as variáveis elencadas para a análise dos agentes mencionados (local de nascimento; informações referentes aos seus antepassados, escolarização e profissão dos agentes). Nota-se a partir disso, que há uma regularidade entre eles por serem oriundos do estado do Maranhão, e um deles ter nascido na capital do estado do Maranhão, São Luís, confere com uma singularidade entre os pares. Dos três agentes em destaque, Joaquim Elias Nagib Pinto Haickel, passou por dois colégios no $2^{\circ}$ grau (ensino médio), colégio Dom Bosco e Batista, escolas particulares na capital do estado do Maranhão. E José Jorge Leite Soares concluiu o $2^{\circ}$ grau (ensino médio) no Colégio Elefante Branco, escola da rede de ensino estadual localizada em Brasília - DF.

E no que tange ao curso de graduação, dois deles fizeram o curso de Direito (Joaquim Elias Nagib Pinto Haickel e Washington Luiz) e José Jorge Leite concluiu o curso de engenharia e destaca-se entre os demais por ter especializações e ter feito estágios fora do Brasil. O último agente do quadro, Washington Luiz, ainda possui um segundo curso de graduação em Administração.

Dentre as instituições onde concluíram seus respectivos cursos de graduação, somente José Jorge Leite concluiu na Universidade de Brasília (UNB), fora do estado do maranhão, e os demais concluíram em instituição pública do Maranhão (UFMA). 
GARCES, K. C. R. Perfis sociais, produção cultural e atuação política dos membros do Instituto Histórico e Geográfico do Maranhão

Em relação às profissões dos agentes, nota-se que José Jorge Leite e Washington

Luiz exerceram atividades ligadas aos cursos de graduação. E Joaquim Elias Nagib Pinto

Haickel não seguiu atividades ligadas a carreira de advogado e enveredou somente pelos âmbitos da política e literatura.

QUADRO 1 - PERFIS SOCIAIS

\begin{tabular}{|c|c|c|c|c|}
\hline & $\begin{array}{c}\text { LOCAL DE } \\
\text { NASCIMENTO }\end{array}$ & $\begin{array}{c}\text { INFORMAÇÕES SOBRE } \\
\text { ANTEPASSADOS }\end{array}$ & ESCOLARIZAÇÃO & PROFISSÃO \\
\hline $\begin{array}{l}\text { Joaquim } \\
\text { Elias Nagib } \\
\text { Pinto } \\
\text { Haickel } \\
\text { (1) }\end{array}$ & São Luís (MA) & $\begin{array}{l}\text { Avô e avó paternos: Elias } \\
\text { Haickel e Maria Haickel. } \\
\text { Atuações políticas dos } \\
\text { familiares: } \\
\text { Nagib Haickel (pai): } \\
\text { Deputado Federal pelo } \\
\text { Maranhão de } 1979 \text { a 1987; } \\
\text { José Antônio Haickel (tio } \\
\text { por parte de pai): Prefeito de } \\
\text { Pindaré-Mirim. } \\
\text { Profissão dos familiares e } \\
\text { escolarização: } \\
\text { Pai: Não concluiu o ensino } \\
\text { fundamental; comerciante e } \\
\text { político; } \\
\text { Clarisse Pinto Haickel } \\
\text { (mãe): funcionária pública; } \\
\text { Nagib Haickel Filho (irmão } \\
\text { mais novo): empresário. }\end{array}$ & $\begin{array}{l}\text { Ensino médio: Colégio Batista e Colégio } \\
\text { Dom Bosco - ambos localizados em São } \\
\text { Luís (MA). } \\
\text { Graduação: Direito na Universidade } \\
\text { Federal do Maranhão (UFMA). Formou-se } \\
\text { em 1985, em São Luís (MA). }\end{array}$ & $\begin{array}{l}\text { Não seguiu a } \\
\text { carreira de } \\
\text { advogado nem a } \\
\text { acadêmica e } \\
\text { enveredou pela } \\
\text { política e pela } \\
\text { literatura. }\end{array}$ \\
\hline $\begin{array}{l}\text { José Jorge } \\
\text { Leite Soares } \\
\text { (2) }\end{array}$ & Pinheiro (MA) & $\begin{array}{l}\text { Pai e mãe: Orleans Mendes } \\
\text { Soares e Diana Leite Soares. }\end{array}$ & $\begin{array}{l}\text { Ensino médio: Colégio Elefante Branco - } \\
\text { Brasília (DF). } \\
\text { Graduação: Curso de Engenharia } \\
\text { Mecânica na Universidade de Brasília } \\
\text { (UNB). Formou-se em dezembro de 1972, } \\
\text { em Brasília (DF). } \\
\text { Especialização: 1) Especialização na área } \\
\text { de Conservação de Energia; 2) MBA em } \\
\text { Gestão de Serviços Públicos, no Instituto } \\
\text { Superior de Administração e Negócios } \\
\text { (ISAM) da Fundação Getúlio Vargas, em } \\
\text { São Luís (MA), de } 2003 \text { a 2004. } \\
\text { Estágios internacionais: 1) Departament of } \\
\text { Energy em 1981, em Londres; 2) Spirax } \\
\text { Sarco em 1981, em Chelteham; 3) Nova } \\
\text { Scotia Power Plant em 1988, em Hallifax; 4) } \\
\text { Energy Management Course e Fabrimetal, } \\
\text { em Bruxelas, entre outubro e novembro de } \\
\text { 1989. }\end{array}$ & $\begin{array}{l}\text { Engenheiro e } \\
\text { consultor na área } \\
\text { de engenharia e } \\
\text { professor de } \\
\text { ensino superior e } \\
\text { técnico. }\end{array}$ \\
\hline
\end{tabular}




\begin{tabular}{|c|c|c|c|c|}
\hline $\begin{array}{l}\text { Washington } \\
\text { Luiz Maciel } \\
\text { Cantanhede } \\
\text { (3) }\end{array}$ & $\begin{array}{l}\text { Vitória do } \\
\text { Mearim (MA) }\end{array}$ & $\begin{array}{l}\text { Não foram encontradas } \\
\text { informações até o momento da } \\
\text { pesquisa. }\end{array}$ & $\begin{array}{l}\text { Ensino médio: não há informações. } \\
\text { Graduação: Direito pela Universidade } \\
\text { Federal do Maranhão (UFMA), em São Luís } \\
\text { (MA); curso de Administração pela } \\
\text { Universidade Estadual do Maranhão } \\
\text { (UEMA), em São Luís (MA). }\end{array}$ & $\begin{array}{l}\text { Bancário e } \\
\text { servidor de } \\
\text { Justiça do } \\
\text { Trabalho, } \\
\text { Promotor de } \\
\text { Justiça. }\end{array}$ \\
\hline
\end{tabular}

FONTE: REVISTA DO INSTITUTO HISTÓRICO E GEOGRÁFICO DO MARANHÃO (2013, pg.54-186).

A seguir, o quadro abaixo mostra as informações sobre as inscrições políticas dos três casos analisados. Dentre os cargos eletivos, nota-se que os três possuem cargos como Deputado Federal, Deputado Estadual e Vereador. Até o momento da pesquisa não foram encontradas informações referentes à Washington Luiz no que tange cargos ocupados em burocracias de governos nem em cargos administrativos em escolas/universidades. Também não encontramos informações para Joaquim Elias Nagib Pinto Haickel no que se refere a cargos administrativos em escolas/universidades. Mas em relação a cargos ocupados em burocracias de governos este apresenta cargo como assessor e secretário entre outros. Da mesma forma José Jorge Leite apresenta informações sobre estes cargos. Já no que toca cargos em universidades este assumiu posições de coordenador de curso de graduação.

Em relação aos partidos políticos, dois deles mencionam ligações com determinados partidos, dando ênfase para Joaquim Elias Nagib Pinto Haickel que apresenta uma participação de certa forma constante.

QUADRO 2 - INSCRIÇÕES POLÍTICAS

\begin{tabular}{|c|c|c|c|c|}
\hline & $\begin{array}{l}\text { CARGOS } \\
\text { ELETIVOS }\end{array}$ & $\begin{array}{l}\text { CARGOS OCUPADOS EM } \\
\text { GOVERNOS (SECRETARIAS, } \\
\text { CONSELHOS ETC.) }\end{array}$ & $\begin{array}{c}\text { CARGOS OCUPADOS EM } \\
\text { ESCOLAS E } \\
\text { UNIVERSIDADES }\end{array}$ & PARTIDOS POLÍTICOS \\
\hline (1) & $\begin{array}{l}\text { Deputado Estadual } \\
\text { (1982); Deputado } \\
\text { Federal (1986); } \\
\text { Constituinte. }\end{array}$ & $\begin{array}{l}\text { - Assessor na Assembleia Legislativa } \\
\text { (1978-1979); } \\
\text { - Secretário de Estado de Esportes; } \\
\text { - Oficial de Gabinete do governador } \\
\text { João Castelo; } \\
\text { - Chefe da Casa Civil José Burnet; } \\
\text { - Secretário de Assuntos Políticos } \\
\text { (Governo Lobão); } \\
\text { - Secretário de Educação (Governo } \\
\text { Fiquene); } \\
\text { - Retorno à Assembleia Legislativa } \\
\text { em 1998. }\end{array}$ & $\begin{array}{l}\text { Não foram encontradas } \\
\text { informações até o momento } \\
\text { da pesquisa. }\end{array}$ & $\begin{array}{l}\text { 1) Partido Democrático } \\
\text { Social (PDS) de 1980 a } \\
\text { janeiro de 1986; } \\
\text { 2) Partido do Movimento } \\
\text { Democrático Brasileiro } \\
\text { (PMDB) de 1986 a 1989; } \\
\text { 3) Partido Democrata } \\
\text { Cristão (PDC) de 1989 a } \\
\text { 1990; } \\
\text { 4) Partido Trabalhista } \\
\text { Brasileiro (PTB) de } 1990 \text { a } \\
\text { 1997; } \\
\text { 5) Partido Republicano } \\
\text { Progressista (PRP) durante } \\
\text { alguns meses em 1997; } \\
\text { 6) Retorno ao PTB, de } 1997 \\
\text { a janeiro de 2003; } \\
\text { 7) Partido Socialista }\end{array}$ \\
\hline
\end{tabular}


GARCES, K. C. R. Perfis sociais, produção cultural e atuação política dos membros do Instituto Histórico e Geográfico do Maranhão

\begin{tabular}{|c|l|l|l|l|}
\hline & & & & $\begin{array}{l}\text { Brasileiro (PSB) de janeiro } \\
\text { de 2003 até o final de 2005; } \\
\text { 8) Retorno ao PMDB em } \\
2006 .\end{array}$ \\
\hline (2) & $\begin{array}{l}\text { Deputado Estadual } \\
\text { duas vezes (1995 a } \\
\text { 2002). }\end{array}$ & $\begin{array}{l}\text { - Gerente de Estado de } \\
\text { Desenvolvimento Regional de } \\
\text { Rosário (1999 a 2000); } \\
\text { - Secretário de Estado Extraordinário } \\
\text { de Coordenação das Gerências } \\
\text { Regionais (2002 a 2004); } \\
\text { - Secretário de Estado Extraordinário } \\
\text { no exercício da Gerência de Pinheiro } \\
\text { (2000 a 2001). }\end{array}$ & $\begin{array}{l}\text { Engenharia Mecânica da } \\
\text { Universidade Estadual do } \\
\text { Maranhão (UEMA) de 1974 a } \\
1975 .\end{array}$ & $\begin{array}{l}\text { 1) Partido Progressista (PP) } \\
\text { de 1994 a 2002; } \\
\text { 2) Partido da Frente Liberal } \\
\text { (PFL) desde 2002. }\end{array}$ \\
\hline (3) & $\begin{array}{l}\text { Um mandato de } \\
\text { Vereador. }\end{array}$ & $\begin{array}{l}\text { Não foram encontradas informações } \\
\text { até o momento da pesquisa. }\end{array}$ & $\begin{array}{l}\text { Não foram encontradas } \\
\text { informações até o momento } \\
\text { da pesquisa. }\end{array}$ & $\begin{array}{l}\text { Não foram encontradas } \\
\text { informações até o momento } \\
\text { da pesquisa. }\end{array}$ \\
\hline
\end{tabular}

FONTE: REVISTA INSTITUTO HISTÓRICO E GEOGRÁFICO DO MARANHÃO (2013, pg.54-186).

Dentre as participações em instâncias culturais, nota-se que todos estão envolvidos com Academias, Associações, Institutos entre outros. E dois deles possuem participações em veículos midiáticos, dando ênfase para Joaquim Elias Nagib Pinto Haickel. E todos de alguma maneira foram premiados, condecorados, receberam menções honrosas entre outros no âmbito da cultura.

\section{QUADRO 3 - INSCRIÇÕES CULTURAIS}

\begin{tabular}{|c|c|c|c|}
\hline & $\begin{array}{l}\text { PERTENCIMENTO A INSTÂNCIAS } \\
\text { CULTURAIS }\end{array}$ & $\begin{array}{l}\text { PARTICIPAÇÃO EM } \\
\text { VEÍCULOS } \\
\text { MIDIÁTICOS }\end{array}$ & $\begin{array}{l}\text { PRÊMIOS NA ÁREA DA } \\
\text { CULTURA }\end{array}$ \\
\hline (1) & $\begin{array}{l}\text { Membro da Academia Imperatrizense de Letras; } \\
\text { presidente da Federação Maranhense e vice- } \\
\text { presidente da Confederação Brasileira de tênis; } \\
\text { membro da Associação Desportiva Mirante; } \\
\text { membro fundador do Instituto de Cidadania } \\
\text { Empresarial do Maranhão (ICE); vice-presidente } \\
\text { do Fórum Nacional de Secretários de Esporte e } \\
\text { Lazer; Membro da Fundação Nagib Haickel; } \\
\text { membro do Instituto Histórico e Geográfico do } \\
\text { Maranhão (IHGM). }\end{array}$ & $\begin{array}{l}\text { 1) Fundou em sociedade } \\
\text { com Fernando Sarney a } \\
\text { Rádio e Televisão } \\
\text { Maranhão Central LTDA; } \\
\text { 2) Com Celso Borges e } \\
\text { coadjuvado por Roberto } \\
\text { Kenard, Ivan Sarney, } \\
\text { Ronaldo Braga, e } \\
\text { Nagibinho (seu irmão), } \\
\text { produzia e apresentava o } \\
\text { programa "Em tempo de } \\
\text { Guarnicê", levado ao ar } \\
\text { pela Mirante FM em 1982; } \\
\text { 3) Foi editor da Revista } \\
\text { Guarnicê em 1983. }\end{array}$ & $\begin{array}{l}\text { Premiado no Concurso Cidade de são } \\
\text { Luís; premiado no concurso } \\
\text { SECMA/SIOGE/Civilização } \\
\text { Brasileira, em 1982; recebeu menção } \\
\text { honrosa por um roteiro. }\end{array}$ \\
\hline (2) & $\begin{array}{l}\text { Membro da Academia Pinheirense de Letras, Artes } \\
\text { e Ciências; membro do Instituto Histórico e } \\
\text { Geográfico do Maranhão (IHGM). }\end{array}$ & $\begin{array}{l}\text { Articulista do jornal O } \\
\text { Estado do Maranhão. }\end{array}$ & $\begin{array}{l}\text { Cônsul Honorário da França em São } \\
\text { Luís desde 2004; condecorado com a } \\
\text { medalha Pecurimã (Prefeitura de } \\
\text { Pinheiro); condecorado com a } \\
\text { Medalha Manoel Bequimão } \\
\text { (Assembleia Legislativa do } \\
\text { Maranhão); recebeu a Medalha Mérito } \\
\text { Simão Estácio da Silveira (Câmara } \\
\text { dos vereadores de São Luís); título de }\end{array}$ \\
\hline
\end{tabular}




\begin{tabular}{|l|l|l|l|}
\hline & & $\begin{array}{l}\text { Cidadão de Guimarães; título de } \\
\text { Cidadão de Pedro do Rosário; título de } \\
\text { Cidadão de São Bento; título de } \\
\text { Cidadão de Esperantinópolis. }\end{array}$ \\
\hline (3) & $\begin{array}{l}\text { Membro fundador da Academia Aririense- } \\
\text { Vitoriense de Letras (AVL); membro do Instituto } \\
\text { Histórico e Geográfico do Maranhão (IHGM); } \\
\text { membro da Associação dos Amigos do Arquivo } \\
\begin{array}{l}\text { Público do Estado do Maranhão (APEM); membro } \\
\text { da Associação do Ministério Público Estadual } \\
\text { (AMPEM); membro da Comissão Gestora do } \\
\text { Programa Memória Institucional do Ministério } \\
\text { Público do Maranhão. }\end{array}\end{array}$ & $\begin{array}{l}\text { Não foram encontradas } \\
\text { informações até o } \\
\text { momento da pesquisa. }\end{array}$ & $\begin{array}{l}\text { Premiado cinco vezes (em 1996, 1998, } \\
1999,2001 \text { e 2003) nos concursos } \\
\text { anuais de melhor arrazoado forense do } \\
\text { MP, promovidos pela AMPEM. }\end{array}$ \\
\hline
\end{tabular}

FONTE: REVISTA DO INSTITUTO HISTÓRICO E GEOGRÁFICO DO MARANHÃO (2013, pg.54-186).

Em relação às atividades da escrita todos estão envolvidos com publicações de livros de gêneros e temáticas diversos, dando ênfase a Joaquim Elias Nagib Pinto Haickel que publicou 12 livros.

QUADRO 4 - PRODUÇÃO ESCRITA

\begin{tabular}{|l|l|l|l|l|l|}
\cline { 2 - 6 } & $\begin{array}{c}\text { GÊERRO DE } \\
\text { ESCRITA }\end{array}$ & \multicolumn{1}{|c|}{ TEMÁTICAS } & $\begin{array}{c}\text { PRINCIPAIS } \\
\text { EDITORAS OU } \\
\text { LOCAIS DE } \\
\text { PUBLICAÇÃO }\end{array}$ & $\begin{array}{c}\text { DÉCADA NA QUAL SE } \\
\text { CONCENTRA O MAIOR } \\
\text { NÚMERO DE } \\
\text { PUBLICAÇOES } \\
\text { LOCALIZADAS }\end{array}$ & $\begin{array}{c}\text { NÚMERO DE } \\
\text { LIVROS } \\
\text { PUBLICADOS }\end{array}$ \\
\hline $\mathbf{( 1 )}$ & $\begin{array}{l}\text { Literatura em } \\
\text { geral }\end{array}$ & $\begin{array}{l}\text { Contos, poemas, } \\
\text { coletâneas de discurso, } \\
\text { crônicas, histórias em } \\
\text { quadrinhos }\end{array}$ & Editora Globo & 1980 & 12 \\
\hline $\mathbf{( 2 )}$ & $\begin{array}{l}\text { Literatura } \\
\text { regional }\end{array}$ & Folclore, crônicas & Editora Halley & 2000 & 4 \\
\hline $\mathbf{3})$ & $\begin{array}{l}\text { Historiografia, } \\
\text { biografia }\end{array}$ & $\begin{array}{l}\text { História da cidade de } \\
\text { Vitória do Mearim, } \\
\text { biografia de Celso M. } \\
\text { (a biografia possuiu 85 } \\
\text { páginas). }\end{array}$ & $\begin{array}{l}\text { Editora AMPEM, } \\
\text { Editora Lithograf }\end{array}$ & 1990 & 3 \\
\hline
\end{tabular}

FONTE: REVISTA DO INSTITUTO HISTÓRICO E GEOGRÁFICO DO MARANHÃO (2013, pg.54-186).

\section{CONSIDERAÇÕES FINAIS}

Tendo em vista os dados apresentado nota-se que os membros efetivos do Instituto Histórico e Geográfico do Maranhão (IHGM) possuem um acúmulo de recursos diversos e multidimensionais, que os auxiliam, sobretudo, a galgar posições na pirâmide social. .

Esses recursos variados podem ser observados a partir dos títulos escolares; medalhas e títulos, recebidos de diversas instituições; postos conquistados em esferas do poder público, nos domínios parlamentares, das burocracias acadêmicas e das inscrições 
GARCES, K. C. R. Perfis sociais, produção cultural e atuação política dos membros do Instituto Histórico e Geográfico do Maranhão

militantes; assim como das participações em outras instâncias de consagração ligadas à cultura e das distinções via publicação de livros ou artigos acadêmicos publicados.

Dados que nos permitiram comprovar as diretrizes de análise mobilizadas a partir de Reis e Grill (2016) que indicavam a aposta em tratar tal universo como um domínio de atuação de elites. Uma vez que ele é estruturalmente compósito e marcado pela "justaposição integrada" de lógicas e princípios culturais e políticos, exigindo que os agentes estejam posicionados em domínios variados, mas complementares entre si, e que demonstrem a posse pessoal e personificada de trunfos diversos, adquiridos pelo trânsito efetuado e pelo reconhecimento que as inscrições permitem.

\section{REFERÊNCIAS:}

ANJOS, J. C. G. dos. Intelectuais, literatura e poder em Cabo Verde. Porto Alegre: EDUFRGS, 2002.

BEM-VINDO Joaquim. Disponível em: http://www.blogsoestado.com/leopoldovaz/2011/09/13/bem-vindo-joaquim/. Acesso em: 13 jul. 2016.

BOURDIEU, P. Os usos sociais da ciência: por uma sociologia clínica do campo científico. Tradução de: CATANI, D. B. São Paulo: Fundação Editora da UNESP, 2003.

CHARLE, C. A prosopografia ou biografia coletiva: balanço e perspectivas. In: HEINZ, F. Por outra história das elites. Rio de Janeiro: FGV Editora, 2006.

Como anda a história social das elites e da burguesia? Tentativa de balanço crítico da historiografia contemporânea. In: HEINZ, F. M. Por outra história das elites. Rio de Janeiro: FGV Editora, 2006.

CORADINI, O. L. Panteões, iconoclastas e as ciências sociais. In: FELIX, L. O.; ELMIR, C. (Org.). Mitos e heróis: construção de imaginários. Porto Alegre: Editora da Universidade Universidade Federal do Rio Grande do Sul, 1998.

A formação da elite médica, a Academia Nacional de Medicina e a França como centro de importação. Estudos Históricos, Rio de Janeiro, n. 35, p. 3-22, 2005.

GRILL, I. G.; REIS, E. T. dos. O que escrever quer dizer na política? Carreiras políticas e gêneros de produção escrita. Revista Pós Ciências, São Luís, v. 9, n. 12, 2012.

Intérpretes e notáveis da literatura e da cultura popular do Maranhão. Trabalho apresentado no 40. Encontro Anual da ANPOCS, Caxambu, 2016.

INSTITUTO HISTÓRICO E GEOGRÁFICO DO MARANHÃO (IHGM). Revista do Instituto Histórico e Geográfico do Maranhão, São Luís, n. 27, 2007.

ISSUU. Disponível em: <https://issuu.com/search?q=ihgm>. Acesso em: 13 jul. 2016. 
JOAQUIM Haickel. In: WIKIPÉDIA: a enciclopédia livre. Disponível em: $<$ https://pt.wikipedia.org/wiki/Joaquim_Haickel>. Acesso em: 13 jul. 2016.

POLLACK, M. Memória e identidade social. Revista Estudos Históricos, Rio de Janeiro, v. 5, n. 10, 1992.

QUINTELLA, M. M. D. Cultura e poder ou espelho, espelho meu: existe alguém mais culto do que eu? In: MICELI, S. (Org.). Estado e cultura no Brasil. São Paulo: Difel, 1984.

REIS, E. T. dos. Saberes em movimento: transações entre "intelectuais", definições de ciências sociais e a "política". In: GRILL, I. G.; SEIDL, E. (Org.). As ciências sociais e os espaços da política no Brasil. Rio de Janeiro: Editora FGV, 2013.

SCHWARCZ, L. M. Os Institutos Históricos e Geográficos. In: O espetáculo das raças: cientistas, instituições e questão racial no Brasil - 1870-1930. São Paulo: Companhia das Letras, 1993. 